\title{
Editorial
}

\section{Head and neck oncology: Where are we heading?}

Head and neck oncology is an evolving specialty demanding expertise in various disciplines and exposure to many specialties. In the past, the surgeon was in charge of Head and neck cancer patient's care from diagnosis till death. Now the surgeon is part of the multidisciplinary team that makes treatment decisions. We have moved headway to develop guidelines for various head and neck cancers on evidence-based medicine. Our aim was to bring about the change from the individualized approach to algorithm specified therapy. The convergence of opinion through evidence-based medicine is the accepted course of action. What matters is our loyalty to our patients and not our hope of curing all cancers.

For the last two decades, the management of head and neck cancers has been characterized by profound changes, both triggered by the willingness of oncologists to reshape significantly their conceptual approaches to locally advanced diseases and facilitated by the advent of newer technologies. Indeed, the potentialities of functional imaging, the significant progress in conservative surgery and reconstruction, the acknowledged role of concurrent chemo-radiation and the advent of targeted therapies are among the main tracks along which fundamental changes in the philosophy of management have been recently observed. Coincident with this is the need to move progressively to a much more holistic approach, taking greater account of the quality of life after treatment.

The first issue of this journal is aimed at showing how considerable are today's efforts toward improving treatment outcomes for head and neck cancer patients. This willingness to make significant and rapid progress probably derives from the fact that rarely in oncology are treatment failures more readily visible and functionally impairing than in these patients. This together with the fact that head and neck cancer is a "big killer" worldwide and Asia, in particular, fully justifies the intensive translational and clinical research that fosters and optimizes our ways to plan and deliver treatments.

This journal is also designed and written with the intent of providing oncologists with a broad, comprehensive, and balanced view of both consolidated and innovative concepts. Its objective is to help practitioners understand better the mechanisms that drive the development of cancer, as well as revisit, the evidence-based data and complexities of decision-making in this field.

AK Dewan

Department of Surgical Oncology, Rajiv Gandhi Cancer Institute, New Delhi, India

Address for correspondence: Dr. AK Dewan, Medical Director and Chief Head and Neck Oncology Services, Rajiv Gandhi Cancer Institute, New Delhi, India. E-mail: dewan.ajay@gmail.com

This is an open access article distributed under the terms of the Creative Commons Attribution-NonCommercial-ShareAlike 3.0 License, which allows others to remix, tweak, and build upon the work non-commercially, as long as the author is credited and the new creations are licensed under the identical terms.

\begin{tabular}{|l|c|}
\hline \multicolumn{2}{|c|}{ Access this article online } \\
\hline \multirow{2}{*}{$\begin{array}{l}\text { Website: } \\
\text { www.asjo.in }\end{array}$} & Quick Response Code \\
\hline DOI: & \\
10.4103/2454-6798.165082 &
\end{tabular}

How to cite this article: Dewan AK. Head and neck oncology: Where are we heading? Asian J Oncol 2015;1:1. 